\title{
PENGARUH PERBANDINGAN SODIUM CARBOXY METHYL CELLULOSE (CMC Na) TERHADAP UJI FISIK GEL EKSTRAK DAUN TEH HIJAU (Camelia sinensis L.)
}

\section{The Influence Of Sodium Carboxy Methyl Cellulose (Cmc Na) On Physical Test Extract Gel Green Tea Leaf (Camelia Sinensis L.)}

\author{
Kiki Puspitasary ${ }^{1}$, Meliana Novitasari ${ }^{2}$, Nova Rahma Widyaningrum ${ }^{3}$ \\ STIKES Mamba'ul 'Ulum Surakarta \\ kiki.puspi@gmail.com
}

\begin{abstract}
ABSTRAK
Latar belakang : Daun teh hijau dikenal sebagai tanaman yang mengandung senyawa katekin. Senyawa katekin diketahui merupakan antioksidan yang memberikan serapan pada panjang gelombang daerah UV B (290-320) yang dapat digunakan sebagai bahan aktif sediaan tabir surya.

Tujuan Penelitian : Penelitian ini bertujuan untuk membuat gel daun teh hijau serta mengetahui pengaruh perbandingan CMC Na yang digunakan sebagai gelling agent dalam menghasilkan gel dengan sifat fisik baik.

Metode : Simplisia daun teh hijau dibuat ekstrak dengan metode maserasi menggunakan pelarut etanol 96\%. Ekstrak daun teh hijau diformulasikan menjadi sediaan gel dengan gelling agent $\mathrm{CMC} \mathrm{Na}$, dengan perbandingan 3\%, 4,5\%, $6 \%$. Gel daun teh hijau diuji sifat fisiknya meliputi homogenitas, organoleptis, daya sebar, daya lekat, dan $\mathrm{pH}$. Hasil evaluasi sifat fisiknya kemudian dianalisis menggunakan uji statistik parametrik yaitu Shapiro Wilk yang dilanjut uji ANOVA satu jalan.

Hasil : Hasil uji homogenitas menunjukkan hasil yang homogen. Hasil uji organoleptis menunjukkan warna mengalami perubahan dari hijau menjadi hijau kecoklatan, bau mengalami penurunan aroma, konsistensi tidak mengalami perubahan selama penyimpanan. Hasil uji daya sebar yaitu Formula I $34,22 \mathrm{~cm}^{2}$, Formula II $15,10 \mathrm{~cm}^{2}$, Formula III $9,13 \mathrm{~cm}^{2}$ setelah penyimpanan selama tiga minggu. Hasil daya lekat yaitu Formula I 21,72 detik, Formula II 41,63 detik, Formula III 61,44 detik setelah penyimpanan selama tiga minggu. Uji pH Formula I yaitu 5,23, Formula II yaitu 6,37, Formula III yaitu 8,18 setelah penyimpanan selama tiga minggu.

Simpulan : Pertama, ekstrak etanol daun teh hijau (Camellia sinensis L) dapat dibuat sediaan gel dengan variasi basis CMC Na yang mempengaruhi uji evaluasi sifat fisik gel tersebut. Kedua, gel ekstrak daun teh hijau yang mempunyai sifat fisik paling baik adalah Formula II dimana menggunakan CMC Na sebanyak 4,5 $\%$.
\end{abstract}

Kata kunci : Gel, daun teh hijau, CMC Na. 


\begin{abstract}
Background : Green tea leaves are known as plants that contain catechin compounds. Catechin compounds are known to be antioxidants that provide absorption at the wavelength of the UV B region (290-320) which can be used as active ingredients for sunscreen preparations.

The purpose of this study : This study aims to make green tea leaf gel and determine the effect of comparison of CMC Na which is used as a gelling agent in producing gels with good physical properties.

Method: Simplisia green tea leaves are extracted using maceration method using ethanol $96 \%$ solvent. Green tea leaf extract is formulated into gel preparations with CMC Na gelling agent, with a ratio of 3\%, 4.5\%, 6\%. Green tea leaf gel was tested for its physical properties including homogeneity, organoleptic, spreadability, adhesion, and $\mathrm{pH}$. The results of the evaluation of their physical properties were then analyzed using the parametric statistical test, namely Shapiro Wilk, followed by the one-way ANOVA test.

Result : Homogeneity test results show homogeneous results. Organoleptic test results show the color changes from green to brownish green, the odor has decreased aroma, the consistency does not change during storage. The spread test results are Formula I $34.22 \mathrm{~cm} 2$, Formula II $15.10 \mathrm{~cm} 2$, Formula III $9.13 \mathrm{~cm} 2$ after storage for three weeks. The results of adhesion are Formula I 21.72 seconds, Formula II 41.63 seconds, Formula III 61.44 seconds after storage for three weeks. The pH test of Formula I is 5.23, Formula II is 6.37, Formula III is 8.18 after storage for three weeks.

Conclusion : First, ethanol extracts of green tea leaves (Camellia sinensis L) can be made gel preparations with variations of $\mathrm{CMC} N \mathrm{Na}$ bases that affect the evaluation of the physical properties of the gel. Second, green tea leaf extract gel which has the best physical properties is Formula II which uses CMC Na as much as $4.5 \%$.
\end{abstract}

Keywords: Gel, green tea leaves, CMC Na.

\title{
PENDAHULUAN
}

Daun teh hijau banyak dijumpai di Indonesia. Pada era sekarang ini daun teh hijau tidak hanya dimanfaatkan untuk diseduh kemudian diminum saja. Daun teh hijau telah banyak dimanfaatkan dalam dunia kesehatan dan kecantikan sebagai antioksidan.

Daun teh hijau dikenal sebagai tanaman yang mengandung senyawa katekin. Senyawa katekin diketahui merupakan antioksidan yang memberikan serapan pada panjang gelombang daerah UV B (290-320) yang dapat digunakan sebagai bahan aktif sediaan tabir surya (Syah, 2006). Menurut Wulandari (2018), ekstrak etanol teh hijau sebanyak $0,8 \%$ memiliki aktivitas antioksidan dengan ditunjukkan nilai $\mathrm{IC}_{50}$ sebesar 9,696 ppm. Menrut Rahmi (2018), gel esktrak daun teh hijau dengan konsentrasi $7 \%$ mampu menghambat pertumbuhan bakteri 
Propionibacterium acnes yang dapat menyebabkan jerawat. Kandungan polifenol pada dun teh hijau sebanyak 30-40 \% juga berkhasiat sebagai antioksidan (Anindita dkk, 2012).

Daun teh hijau selain sebagai bahan utama minuman juga memiliki banyak khasiat untuk kesehatan, karena memiliki kandungan gizi yang cukup tinggi dan memiliki banyak komponen kimia salah satunya adalah flavonoid. Epigalokatekin galat merupakan turunan flavonoid yang memiliki efek anti inflamasi, antioksidan, antibakteri, antiviral, antienzymatic effects, dan probiotik pada manusia (Sutarna dkk, 2016).

Sediaan gel dalam dunia kecantikan semakin digemari oleh wanita maupun pria, karena aplikasinya yang mudah, tidak lengket,cepat meresap, memberikan efek dingin, dan tidak meninggalkan bekas. CMC Na pada suhu $90^{\circ} \mathrm{C}$ memiliki viskositas yang stabil, hal ini yang akan menyebabkan sediaan gel tetap stabil pada suhu tinggi (Aliu et al. 2016).

CMC Na banyak digunakan dalam pembuatan sediaan farmasi dikarenakan sifatnya yang netral dan tidak mempengaruhi zat aktif atau obat lain. Selain itu CMC Na juga lebih mudah diperoleh dan memiliki rentang harga yang terjangkau. Sifat CMC Na yang mudah larut dalam air juga menjadi hal penting dalam pemilihannya sebagai gelling agent dalam pembuatan gel.

Tujuan dari penelitian ini adalah yang pertama untuk mengetahui apakah ekstrak daun teh hijau dapat dibuat sediaan gel. Kedua, untuk mengetahui berapakah konsentrasi CMC Na yang digunakan untuk menghasilkan gel dengan sifat fisik yang baik.

\section{METODE PENELITIAN}

Bahan dan alat

Bahan yang digunakan adalah: daun teh hijau yang diperoleh di daerah Tawang mangu, Karanganyar. Bahan kimia yang digunakan adalah etanol $96 \%$, Metil paraben (PT. Dexa Medica, Palembang), Propil paraben (PT. Dexa Medica, Palembang), Parfum teh hijau (Chimultiguna, Indramayu), propilenglikol (PT. Dexa Medica, Palembang). Alat-alat yang digunakan meliputi timbangan miligram, ayakan nomor 60 , oven, beaker glass, cawan porselin, mortier, stamfer, seperangkat alat uji daya sebar, seperangkat alat uji daya lekat.

Pembuatan ekstrak daun teh hijau

Pembuatan ekstrak daun teh hijau menggunakan metode maserasi. Simplisia daun teh hijau sebanyak $1,5 \mathrm{~kg}$ diserbukan dengan mesh 4/18, serbuk daun teh hijau di campur pelarut etanol $96 \%$ dengan perbandingan 1:10 L, campuran serbuk daun teh hijau dan pelarut etanol diaduk selama 3 jam kemudian diendapkan selama 32 jam. Pemisahan antara ampas dan pelarut dilakukan dengan cara penyaringan menggunakan kertas khusus penyaring. Ampas daun teh hijau dibuang dan ekstrak cair daun teh hijau diuapkan sehingga didapat ekstrak kental dengan randemen.

Rancangan formula gel daun teh hijau

Formula Gel ekstrak etanol daun teh hijau : 
Tabel 1. Rancangan formula I, II, III gel ekstrak etanol daun teh hijau

\begin{tabular}{cccc}
\hline Nama Bahan & Formula I & Formula II & Formula III \\
\hline Ekstrak etanol daun teh hijau & $5 \%$ & $5 \%$ & $5 \%$ \\
CMC Na & $3 \%$ & $4,5 \%$ & $6 \%$ \\
Metil paraben & $0,2 \%$ & $0,2 \%$ & $0,2 \%$ \\
Propil Paraben & $0,3 \%$ & $0,3 \%$ & $0,3 \%$ \\
Gliserin & $25 \%$ & $25 \%$ & $25 \%$ \\
Propilen Glikol & $10 \%$ & $10 \%$ & $10 \%$ \\
Parfum & $0,5 \%$ & $0,5 \%$ & $0,5 \%$ \\
Aqua sampai & $100 \%$ & $100 \%$ & $100 \%$ \\
\hline
\end{tabular}

Pengujian Sifat Fisik Sediaan Gel Ekstrak Etanol Daun Teh Hijau

1. Uji homogenitas gel

Uji homogenitas dilakukan dengan cara mengoleskan 3 bagian atas, tengah dan bawah dari gel pada kaca transparan. Homogenitas ditunjukkan dengan tidak adanya butiran kasar pada sediaan. Pengujian pertama dilakukan pada hari sediaan gel dibuat setelah jadi gel langsung diuji homogenitasnya. Sediaan gel kemudian disimpan selama satu minggu dan diuji lagi homogenitasnya, begitu seterusnya setiap minggu selama satu bulan (Sayuti, 2015).

2. Uji daya sebar gel

Uji daya sebar dilakukan untuk menjamin pemerataan gel saat diaplikasikan pada kulit. Gel ditimbang sebanyak 0,5 gram kemudian diletakkan ditengah kaca bulat berskala. Di atas gel diletakkan kaca bulat lain atau bahan transparan lain dan pemberat sehingga berat kaca bulat dan pemberat sampai 250 gram (50 gram, 100 gram, 150 gram, 200 gram, 250 gram), didiamkan selama 1 menit, kemudian dicatat jari-jari penyebarannya dan hitung luas penyebarannya. Daya sebar gel yang baik antara 5-7 cm (Sayuti, 2015).

3. Uji daya lekat gel

Uji ini dilakukan dengan alat-alat seperti alat tes melekat gel. Dua objek glass, stopwatch, anak timbangan gram dan dilakukan dengan cara melekatkan gel secukupnya di atas objek glass yang lain di atas gel tersebut kemudian ditekan dengan beban $1 \mathrm{~kg}$ selama 5 menit kemudian pasang objek gelas pada alat tes setelah itu lepaskan beban seberat 80 gram dan dicatat waktunya hingga kedua objek tersebut terlepas diulangi cara diatas pada setiap formula masing-masing 3 kali. Pengujian pertama dilakukan pada hari sediaan gel dibuat setelah jadi gel langsung diuji daya melekatnya. Sediaan gel kemudian disimpan selama satu minggu dan diuji daya lekatnya, begitu seterusnya setiap minggu selama satu bulan (Ansel, 2005).

4. Uji pH

Penentuan $\mathrm{pH}$ dilakukan dengan menggunakkan stik $\mathrm{pH}$, yaitu dicelupkan dan diamati perubahan warna dicocokkan dengan standar $\mathrm{pH}$ universal. $\mathrm{pH}$ sediaan yang memenuhi kriteria $\mathrm{pH}$ kulit yaitu dalam interval 4,5-6,5. Replikasi dilakukan 3 kali (Sayuti, 2015).

5. Uji Organoleptis

Pengamatan organoleptis meliputi pengamatan bentuk, warna dan bau dari sediaan gel (Ansel, 2005). 


\section{HASIL DAN PEMBAHASAN}

Hasil Pengeringan dan Pembuatan Serbuk

Daun teh hijau dikeringkan dalam oven pada suhu $40^{\circ} \mathrm{C}$, kemudian diblender dan disaring menggunakan ayakan nomor 60. Bahan yang telah kering mempermudah proses penyerbukan, daun teh hijau yang telah dikeringkan dihitung bobot kering terhadap bobot basah daun teh hijau. Hasil rendemen berat daun teh hijau terhadap berat basah yakni dari berat daun teh hijau basah $2500 \mathrm{~g}$ diperoleh berat serbuk kering daun teh hijau $1326 \mathrm{~g}$ sehingga rendemennya adalah $53,04 \%$.

Hasil uji kadar air serbuk daun teh hijau

Tabel 2. Hasil uji kadar air serbuk teh hijau.

\begin{tabular}{cccc}
\hline No & Bobot awal $(\mathrm{g})$ & Bobot bahan $(\mathrm{g})$ & Prosentase $(\%)$ \\
\hline 1 & 1,994 & 0.170 & 8,52 \\
2 & 1,986 & 0,166 & 8,35 \\
3 & 1,998 & 0,168 & 8,40 \\
& & Rata-rata & 8,42 \\
\hline
\end{tabular}

Rata-rata kadar air serbuk daun jengkol yang dilakukan dengan alat moisture balance yaitu $8,42 \%$. Kadar air serbuk daun jengkol memenuhi syarat dimana kadar air suatu serbuk simplisia tidak boleh lebih dari 10\% (Depkes RI, 2015).

Pembuatan ekstrak daun teh hijau

Ekstrak daun teh hijau dibuat dengan metode maserasi. Sebanyak 100 gram daun teh hijau kering diekstrak menggunakan etanol 96\% sebanyak 1 L. Proses maserasi selama 32 jam dengan pengadukan diawal selama 3 jam. Ekstrak cair disaring menggunakan kertas saring kemudian diuapkan menggunakan water bath dengan suhu $70^{\circ} \mathrm{C}$ sampai didapatkan ekstrak kental.

Perhitungan hasil rendemen ekstrak kental teh hijau :

Tabel 3. Hasil prosentase rendemen ekstrak maserasi daun teh hijau.

\begin{tabular}{cccc}
\hline Pelarut & Serbuk (gram) & Ekstrak (gram) & Rendemen $(\%$ b/b) \\
\hline Ethanol $96 \%$ & 150,240 & 26,188 & 17,43 \\
\hline
\end{tabular}

Hasil Pengujian Stabilitas Fisik Gel

Uji organoleptis

Pemeriksaan organoleptis dilakukan untuk mendiskripsikan warna, bau dan konsistensi, sediaan yang dihasilkan sebaiknya memiliki warna yang menarik, bau yang menyenangkan dan konsistensi yang bagus. 
Tabel 4. Hasil organoleptis sediaan gel ekstrak daun teh hijau dengan berbagai konsentrasi CMC Na.

\begin{tabular}{ccccc}
\hline Pemeriksaan & Waktu & Formula I & Formula II & Formula III \\
& Minggu 0 & Hijau & Hijau & Hijau \\
Warna & Minggu 1 & Hijau kecoklatan & Hijau kecoklatan & Hijau kecoklatan \\
& Minggu 2 & Hijau kecoklatan & Hijau kecoklatan & Hijau kecoklatan \\
& Minggu 3 & Hijau kecoklatan & Hijau kecoklatan & Hijau kecoklatan \\
\hline Bau & Minggu 0 & Wangi & Wangi & Wangi \\
& Minggu 1 & Agak wangi & Agak wangi & Agak wangi \\
& Minggu 2 & Agak wangi & Agak wangi & Agak wangi \\
& Minggu 3 & Agak wangi & Agak wangi & Agak wangi \\
\hline Konsistensi & Minggu 0 & Agak kental & Kental & Sangat kental \\
& Minggu 1 & Agak kental & Kental & Sangat kental \\
& Minggu 2 & Agak kental & Kental & Sangat kental \\
& Minggu 3 & Agak kental & Kental & Sangat kental \\
\hline
\end{tabular}

Tabel 4 menunjukkan bahwa minggu pertama gel mengalami warna hijau kemudian setelah mengalami penyimpanan selama satu minggu, dua minggu dan tiga minggu warna gel mengalami perubahan, yaitu gel berwarna hijau kecoklatan. Hal ini dikarenakan daun teh hijau banyak mengandung antioksidan. Sehingga dengan adanya faktor penyimpanan yang kurang maksimal yaitu terkena cahaya maka gel teh hijau mengalami oksidasi sehingga terjadi perubahan warna. Bau yang dihasilkan karena pengaruh pemberian aroma teh hijau yaitu berupa minyak teh hijau. Setelah pembuatan gel mempunyai aroma teh hijau yang kuat tetapi setelah penyimpanan selama seminggu aroma teh hijau mengalami pengurangan. Hal yang sama terjadi pada penyimpanan selama dua minggu dan tiga minggu. Sediaan gel menggunakan konsentrasi gelling agent yang berbedabeda dalam tiap formula yang dapat menyebabkan perbedaan konsistensi tiap formula. Konsistensi gel beberapa saat setelah pembuatan dengan konsistensi gel setelah seminggu penyimpanan adalah tetap sama dan tidak ada peningkatan konsistensi.

Uji Homogenitas

Hasil pengamatan terhadap homogenitas warna gel esktrak daun teh hijau menunjukkan bahwa keempat formula memiliki homogenitas warna yang baik karena warna hijau yang merata pada basisnya selain itu selama penyimpanan pada suhu kamar tidak mengalami perubahan fisik dalam hal homogenitasnya. Hal ini disebabkan pada proses pembuatan gel semua bahan yang digunakan untuk pembuatan gel ekstrak daun teh hijau ini tercampur dengan sempurna sehingga menghasilkan produk yang homogen.

Tabel 5. Hasil homogenitas sediaan gel ekstrak daun teh hijau dengan berbagai konsentrasi CMC Na.

\begin{tabular}{cccc}
\hline Formula & Formula 1 & Formula II & Formula III \\
\hline Minggu 0 & Homogen & Homogen & Homogen \\
Minggu 1 & Homogen & Homogen & Homogen \\
Minggu 2 & Homogen & Homogen & Homogen \\
Minggu 3 & Homogen & Homogen & Homogen \\
\hline
\end{tabular}

Uji Daya Sebar

Pengaruh Perbandingan Sodium Carboxy Methyl Cellulose (CMC Na) Terhadap Uji Fisik Gel Ekstrak Daun Teh Hijau (Camelia Sinensis L.) (Kiki Puspitasary, Meliana Novitasari, Nova Rahma Widyaningrum) 
Hasil pengukuran terhadap daya sebar gel menunjukkan bahwa ketiga formula tidak mengalami penurunan daya sebar selama proses penyimpanan. Hal ini disebabkan karena viskositas yang dimiliki oleh ketiga formula gel tersebut adalah stabil.

Tabel 6. Hasil daya sebar sediaan gel ekstrak daun teh hijau dengan berbagai konsentrasi CMC Na.

\begin{tabular}{|c|c|c|c|c|c|}
\hline \multirow{2}{*}{ Formula } & \multicolumn{5}{|c|}{ Luas penyebaran $\left(\mathrm{cm}^{2} \pm \mathrm{SD}\right)$} \\
\hline & Beban (gram) & Minggu 0 & Minggu 1 & Minggu 2 & Minggu 3 \\
\hline \multirow{5}{*}{$\begin{array}{c}\text { Formula } \\
\text { I }\end{array}$} & 50 & $17,59 \pm 7,19$ & $15,67 \pm 6,02$ & $15,71 \pm 6,29$ & $14,75 \pm 6,33$ \\
\hline & 100 & $22,42 \pm 7,74$ & $18,11 \pm 6,01$ & $18,64 \pm 6,53$ & $18,60 \pm 5,25$ \\
\hline & 150 & $27,11 \pm 8,43$ & $21,80 \pm 5,93$ & $22,97 \pm 6,54$ & $22,34 \pm 4,06$ \\
\hline & 200 & $32,85 \pm 8,60$ & $27,11 \pm 5,90$ & $27,07 \pm 6,55$ & $28,28 \pm 1,97$ \\
\hline & 250 & $37,78 \pm 7,86$ & $36,24 \pm 5,89$ & $35,51 \pm 6,71$ & $34,22 \pm 0,00$ \\
\hline \multirow{5}{*}{$\begin{array}{c}\text { Formula } \\
\text { II }\end{array}$} & 50 & $10,56 \pm 2,30$ & $10,95 \pm 2,34$ & $11,34 \pm 2,24$ & $10,95 \pm 2,07$ \\
\hline & 100 & $12,56 \pm 2,18$ & $12,99 \pm 2,23$ & $12,99 \pm 2,55$ & $12,99 \pm 1,50$ \\
\hline & 150 & $15,30 \pm 2,13$ & $14,30 \pm 2,23$ & $13,22 \pm 2,55$ & $13,30 \pm 1,17$ \\
\hline & 200 & $17,67 \pm 2,13$ & $16,16 \pm 2,24$ & $15,73 \pm 2,55$ & $14,62 \pm 0,94$ \\
\hline & 250 & $18,10 \pm 2,20$ & $17,12 \pm 2,31$ & $16,21 \pm 2,38$ & $15,10 \pm 0,00$ \\
\hline \multirow{5}{*}{$\begin{array}{c}\text { Formula } \\
\text { III }\end{array}$} & 50 & $6,31 \pm 1,71$ & $5,78 \pm 1,61$ & $5,04 \pm 1,52$ & $4,78 \pm 1,38$ \\
\hline & 100 & $8,15 \pm 1,85$ & $7,19 \pm 1,55$ & $6,87 \pm 1,59$ & $5,59 \pm 1,16$ \\
\hline & 150 & $9,39 \pm 1,94$ & $8,46 \pm 1,51$ & $7,67 \pm 1,63$ & $6,46 \pm 0,93$ \\
\hline & 200 & $10,38 \pm 1,96$ & $9,39 \pm 1,50$ & $8,71 \pm 1,64$ & $7,39 \pm 0,67$ \\
\hline & 250 & $11,19 \pm 1,87$ & $10,44 \pm 1,52$ & $9,74 \pm 1,61$ & $9,13 \pm 0,00$ \\
\hline
\end{tabular}

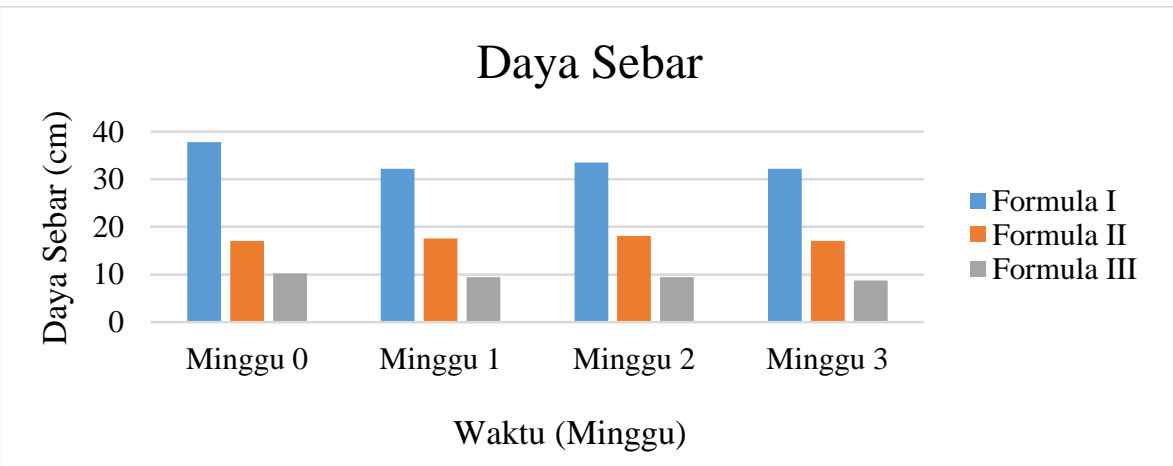

Gambar 1. Histogram daya sebar gel ekstrak daun teh hijau.

Daya Lekat

Daya lekat suatu sediaan gel dinyatakan sebagai lamanya waktu lekat dari dua gelas obyek yang dilapisi gel, daya lekat suatu gel diharapkan dapat menggambarkan kemampuan gel melekat pada tempat aplikasi (kulit) ketika gel digunakan. Semakin besar daya lekat maka semakin lama kontak antara gel dengan kulit sehingga semakin efektif dalam penghantaran obat. 
Tabel 7. Hasil daya lekat gel ekstrak daun teh hijau dengan berbagai konsentrasi CMC Na.

\begin{tabular}{cccc}
\hline $\begin{array}{c}\text { Pemeriksaan } \\
\text { waktu }\end{array}$ & $\begin{array}{c}\text { Formula I } \\
\text { (detik) }\end{array}$ & $\begin{array}{c}\text { Formula II } \\
\text { (detik) }\end{array}$ & $\begin{array}{c}\text { Formula III } \\
\text { (detik) }\end{array}$ \\
\hline Minggu 0 & $20,47 \pm 0,495$ & $39,90 \pm 0,64$ & $60,67 \pm 0,36$ \\
\hline Minggu 1 & $21,62 \pm 0,20$ & $40,91 \pm 0,30$ & $61,40 \pm 0,09$ \\
\hline Minggu 2 & $21,25 \pm 0,23$ & $41,24 \pm 0,19$ & $61,61 \pm 0,08$ \\
\hline Minggu 3 & $21,72 \pm 0,49$ & $41,63 \pm 0,19$ & $61,44 \pm 0,36$ \\
\hline
\end{tabular}

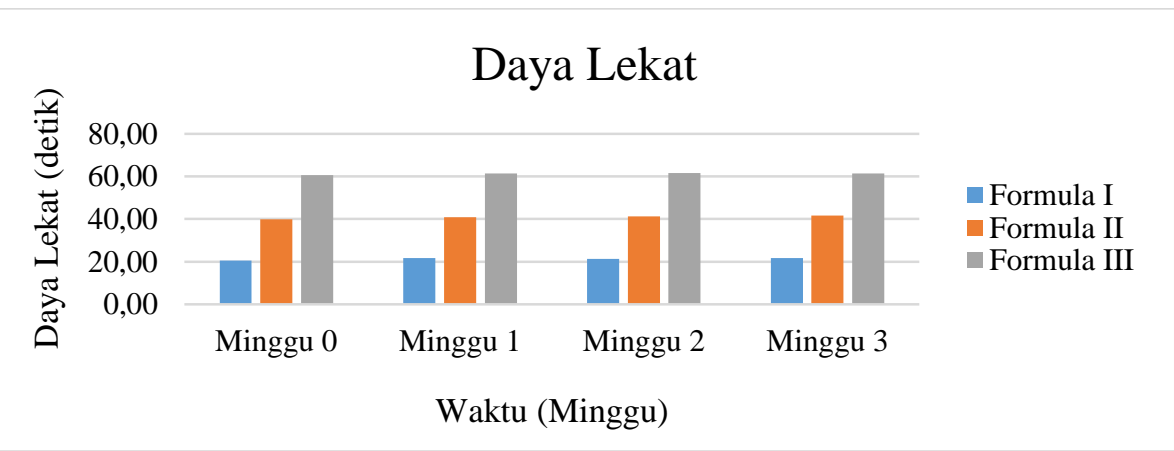

Gambar 2. Histogram hasil daya lekat sediaan gel ekstrak daun teh hijau.

Pengamatan daya lekat gel tiap minggu menunjukkan bahwa semakin besar konsentrasi CMC Na yang digunakan semakin besar daya lekat. Selama penyimpanan tidak terjadi perubahan nilai daya lekat. Hal ini dapat disebabkan karena kondisi viskositas gel yang stabil. Hasil pengukuran terhadap daya sebar gel menunjukkan bahwa ketiga formula tidak mengalami penurunan daya sebar selama proses penyimpanan. Hal ini disebabkan karena viskositas yang dimiliki oleh ketiga formula gel tersebut adalah stabil.

$\mathrm{pH}$

Uji pH dilakukan untuk mengetahui tingkat keasaman dari sediaan gel yang dibuat. Tingkat keasaman gel perlu diketahui untuk menjamin sediaan gel tidak menyebabkan iritasi pada kulit ketika diaplikasikan. Hasil uji $\mathrm{pH}$ sediaan gel ekstrak daun teh hijau dapat dilihat pada tabel

Tabel 8. Hasil uji pH gel ekstrak daun teh hijau dengan berbagai konsentrasi

CMC Na.

\begin{tabular}{cccc}
\hline $\begin{array}{c}\text { Pemeriksaan } \\
\text { waktu }\end{array}$ & $\begin{array}{c}\text { Formula I } \\
\text { (detik) }\end{array}$ & $\begin{array}{c}\text { Formula II } \\
\text { (detik) }\end{array}$ & $\begin{array}{c}\text { Formula III } \\
\text { (detik) }\end{array}$ \\
\hline Minggu 0 & $5,33 \pm 0,04$ & $6,44 \pm 0,03$ & $8,33 \pm 0,06$ \\
\hline Minggu 1 & $5,28 \pm 0,02$ & $6,42 \pm 0,02$ & $8,23 \pm 0,02$ \\
\hline Minggu 2 & $5,24 \pm 0,02$ & $6,39 \pm 0,01$ & $8,20 \pm 0,01$ \\
\hline Minggu 3 & $5,23 \pm 0,02$ & $6,37 \pm 0,01$ & $8,18 \pm 0,01$ \\
\hline
\end{tabular}




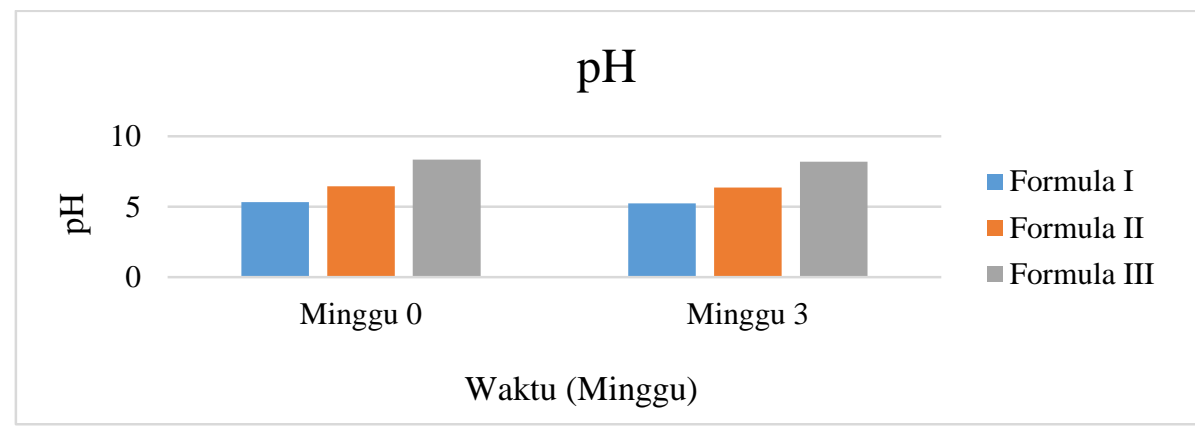

Gambar 3. Histogram hasil uji pH gel ekstrak daun teh hijau.

Hasil uji $\mathrm{pH}$ menunjukkan adanya peningkatan nilai $\mathrm{pH}$ bersamaan dengan meningkatnya konsentrasi CMC Na. Selama proses penyimpanan nilai $\mathrm{pH}$ tetap stabil tidak mengalami peningkatan yang signifikan.

\section{SIMPULAN DAN SARAN}

\section{Simpulan}

Berdasarkan hasil pengamatan dapat disimpulkan bahwa, Pertama, ekstrak etanol daun teh hijau (Camellia sinensis L) dapat dibuat sediaan gel dengan variasi basis $\mathrm{CMC} \mathrm{Na}$ yang mempengaruhi uji evaluasi sifat fisik gel tersebut. Kedua, gel ekstrak daun teh hijau yang mempunyai sifat fisik paling baik adalah Formula II dimana menggunakan CMC Na sebanyak 4,5\%.

\section{Saran}

Berdasarkan kesimpulan penelitian, saran yang dapat disampaikan yaitu Pertama, perlu dilakukan penelitian lebih lanjut terhadap gel teh hijau dengan kombinasi gelling agent $\mathrm{CMC} \mathrm{Na}$ dengan gelling agent yang lain untuk mengetahui sifat fisik gel. Kedua, perlu dilakukan uji daya antioksidan gel daun teh hijau dengan menggunakan metode yang sesuai.

\section{DAFTAR PUSTAKA}

Aliu, A. O., Guo, J., Wang, S., \& Zhao, X. (2016). Hydraulic fracture fluid for gas reservoirs in petroleum engineering applications using sodium carboxy methyl cellulose as gelling agent. Journal of Natural Gas Science and Engineering, 32, 491-500.

Anindita, R., Soeprobowati, T. R., \& Suprapti, N. H. (2012). Potensi teh hijau (Camelia sinensis L.) dalam perbaikan fungsi hepar pada mencit yang diinduksi monosodium glutamat (MSG). ANATOMI dan FISIOLOGI, 20(2), 15-23.

Ansel, H. C., 2005, Pengantar Sediaan Bentuk Farmasi, 599-600, Universitas Indonesia press, Jakarta.

Depkes RI., 2015, Farmakope Indonesia. Edisi V. Departemen Kesehatan Republik Indonesia, Jakarta. 
Rahmi, H., Ramadhan, R., \& Radjab, N. S. (2018). Pengaruh Konsentrasi Natrium Alginat Terhadap Gel Ekstrak Daun Teh Hijau (Camellia Sinensis L.) Sebagai Inhibitor Tirosinase. PHARMACY: Jurnal Farmasi Indonesia (Pharmaceutical Journal of Indonesia), 14(2), 162-172.

Sayuti, NA. 2015. Formulasi dan Uji Stabilitas Fisik Sediaan Gel Ekstrak Daun Ketepeng Cina (Cassia alata L.). Jurnal Kefarmasian Indonesia, 5(2), 7478.

Sutarna, T. H., Alatas, F., \& Al Hakim, N. A. (2016). Pemanfaatan Ekstrak Daun Teh Hijau (Camellia sinensis L) Sebagai Bahan Aktif Pembuatan Sediaan Gel Tabir Surya. Kartika-Jurnal Ilmiah Farmasi , 4 (2), 32-35.

Syah, andi Nur Alam, Taklukan Penyakit dengan Teh Hijau, agro media pustaka, jakarta, 2006, 1, 7, 37.

Wulandari, E. M. D. (2018). OPTIMASI FORMULASI GEL ANTIOKSIDAN TEH HIJAU (Camellia sinensis L.) DENGAN BASIS OLEUM $C A C A O$ (Doctoral dissertation, University of Muhammadiyah Malang). 